\title{
IMPULSE- RESPONSE ENDORSEMENT OF STRENGTH SUSTAINABILITY IN PAVER BLOCKS INFUSED WITH BIOSORPTED TEXTILE EFFLUENTS
}

\author{
S. Manivel*, G. Premkumar and V. Satya Ramesh Potti \\ ${ }^{1}$ Deparment of Civil Engineering, SRM University, Kattankulathur-603203, Tamil Nadu, India \\ *E-mail: manivelfun@yahoo.com
}

\begin{abstract}
Paver blocks, being the ideal utility blocks, are extensively in vogue for any pavement coverage due to the relatively easier and quick manufacturing process, mass production compatibility and lower unit cost. However the production involves huge usage of potable water that may inflict the availability of the same for building construction. A viable alternative without detrimental to the strength and the other related features of paver blocks would be exploring the usage of treated textile/dyeing industrial waste waters replacing potable water. A biosorption process aided by the coagulation-sedimentation method, using dry powdered water hyacinth leaves and petioles as coagulants is employed. This has the added advantage of harboring the fine bio sediments within the pores of the paver blocks resulting in lower porosities. Subjecting the biosorpted paver blocks to the standard quality tests as per IS coding (15658), empirical regression analyses on Compression strength and Flexural strength to withstand stationary and moving loads were applied. With reference to the curing spells of 3 days, 7 days and 28 days the improvised paver blocks had shown a relative increase attainable in the compressive strength as $4 \%, 3.6 \%$ and $2.4 \%$ respectively. The respective attainable increases in the flexural strengths were observed as $7.9 \%, 8 \%$ and $4.9 \%$ for the same curing spells. The results of this study exemplify the twin prospects viz., minimization of potable water requirement replaced by treated wastewaters and environmental protection by way of hiding the treated wastewater used for the mix within the paver blocks.

Keywords: Paver block, Potable water, Textile/Dyeing industry effluents, water hyacinth, biosorption process, Compressive Strength, Flexural Strength
\end{abstract}

(C) RASĀYAN. All rights reserved

\section{INTRODUCTION}

The never ending process of building construction and allied utility activities warrant an ever changing series of exponentially increasing demand for the potable water to sustain the strength, stability and workability aspects associated with different phase of construction. Such a precarious situation has prompted research related to alternative ways and means of balanced supply of equally good quality water from all possible sources including the treated effluents designated within the permissible quality criteria range $^{1}$. However the unmatched potable quality of water is very difficult to obtain in as much as advanced technologies like the reverse osmosis or biosorption need to be employed. Since the arena of manufacturing paver blocks comes under the complementary utility domain, the reverse osmosis process which is perfectly fitting the drinking water qualities is not applicable compared to the pertinent biosorption process that may yield relatively good quality water to sustain the desirable properties of paver blocks ${ }^{2}$. At present most of the industry prone areas of Tamil Nadu state in India are suffocating due to the uncontrollable outcome of waste effluents. Instead of imploring the promising horizon for treatment, reuse and recycling, these hazardous waste waters are simply dumped into potential streams or aerially spread without any treatment, culminating into serious environmental pollution and degradation process. The scope of this paper is limited to exploring the prospects and perspectives of paver blocks infused with biosorpted waste waters, totally replacing the demand for potable water without detrimental to the strength aspects. The mushroom growth water hyacinths available in most of the stagnant water bodies pose a serious threat not only to water resource depletion but also polluting the water and 
atmosphere alike. These malicious bio materials can be transformed into beneficial coagulants facilitating eco friendly biosorption to get good quality water for usage in construction activities ${ }^{3}$.

\section{EXPERIMENTAL}

The eventual transformation of the effluent water into en equivalent potable quality water to be infused in utility building blocks like the paver blocks comprise the following selected unit operations: The dried bio materials obtained from the leafs, petioles and roots of water hyacinth get their granulation to act as a coagulant material that aids in the biological adsorption (Biosorption) of the deleterious components of waste water including the heavy metals and colour. This grade of water finally obtained even as containing very minute sediments will not only replace the demand for potable water but also will help fill up the micro pores of the final product thereby enhancing its strength on a sustainable basis.

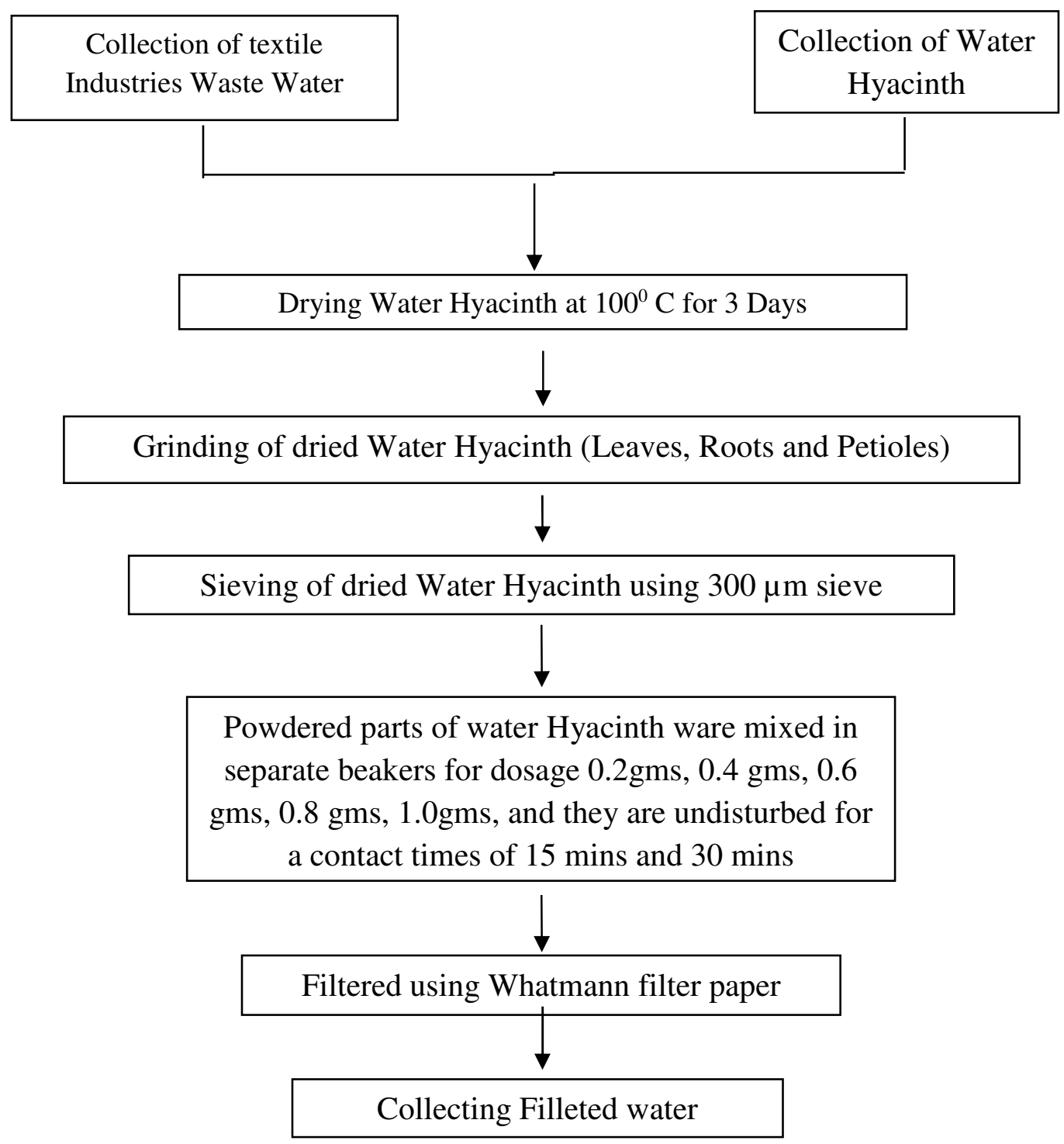

Flow Chart-1

Since the paver blocks are subjected to periodic rains the redundant unwanted harmful elements even from within the block are likely to be expelled and leached down. The biosorpted materials thus obtained 
were mixed with the effluent undergoing treatment at desired dilution levels to prompt the coagulation process by way of subjecting the contents to a centrifugal stirring for about 30 minutes.

\section{RESULTS AND DISCUSSION}

From the utility angle of view a paver block is supposed to exhibit a high order of interlocking facilitating stationary and moving loads not to cause the failure of any individual block concocted with in the frame work of the paver surface. Besides, the power block being the utility block without mortar filling between the inter spaces of the individual paver edges, the paver area should be capable of transmitting the drainage water during rains down through the interconnected and interlocked peripheral space. This facilitates the vertical percolation of stagnating rain waters at relatively faster rates into the subsurface through the cushioning sand layer as the interface between the paver surface and the subsurface stratum. However, during this process a good quality paver block should not by itself absorb and transmit water to imbibe a very low porosity of individual block. Hence a paver block warrants not only the test criteria related to compressive strength, Split tensile strength, flexural strength but also water absorption test similar to the concrete building block. The null hypothesis behind the horizontally laid interlocking concrete paver blocks is that a C-S-H gel is supposed to from within the block acting as a water repellent agent thus minimizing the porosity and the water absorption, in the absence of mortar filling and plastering.

\section{Impulse of biosorption water on the relative porosity response in paver block}

According to the IS: $15658-2006$ any prefabricated concrete block is supposed to have a limiting porosity of $6 \%$ only be it a building block or a utility block like the paver block. By and large, when potable quality of water is used in the immersion test, it finds an easy way infiltrating into the interconnected micro pores of the blocks. When such biosorption quality water derived from the textile and dyeing industries is used, the infiltration and seepage through the interconnected pores of the paver blocks will be hampered due to the presence of the minute sediments and biological matter. Hence the relative porosity reduction exhibited by the reduced water absorption by using water from biosorption sources will be an added advantage besides saving in the need of potable water that is likely to in cure significant cost element. The present study endorsed the complementary advantage of using biosorption water by reducing the cost of importing potable water by about $80 \%$.

An industrial standard hexagonal interlocking concrete paver block of side length $12.5 \mathrm{~cm}$ with a standard thickness of $5 \mathrm{~cm}$ made with potable water for concrete mix was used in replications to find out the dry porosity as the control for comparison. From the geometry of this hexagonal block the surface area normal to loading was found as $412.5 \mathrm{~cm}^{2}$ and the corresponding block volume $2062.50 \mathrm{~cm}^{3}$. The block was immersed in a water bath for 24 hours and the wet weight of the block was found to be $5.30 \mathrm{kgs}$. The initial dry weight of the block individual was found to be $4.96 \mathrm{kgs}$. Hence the saturated porosity is $6.8 \%$.

In case of the paver block with the biosorpted water usage the specific gravity of the bio materials laden water was found to be $1.02 \mathrm{~g} / \mathrm{cc}$. The dry weight of the biosorpted paver block was found to be $4.98 \mathrm{~kg}$ and the wet weight of the block at saturation was found to be $5.25 \mathrm{~kg}$. Hence the saturated porosity $5.4 \%$ this implies that even as the biosorpted water has contributed its sediments within the concrete pores upon absorption and consequence drying, the relative porosity was found to decrease compare to the conventional concrete paver. Hence the biosorption concrete paver blocks are relatively impervious compared to conventional concrete blocks without detrimental to the normal load bearing capacity with moving or dead loads.

By trial and error the moving loads and dead loads were varied from a low weight auto rickshaw (0.300tons) to a heavy truck (2.5tons) subjecting to a wear and tear for seven continuous days. However, the biosorption concrete paver blocks remained intact without any cracks. In case of the conventional paver block the water absorption by way of porosity has been controlled to $6.8 \%$ within prescribed limits. In case of biosorption paver block the porosity was further decreased to $5.4 \%$ indicating clearly that the relative water absorption in significantly low due to the chocking of pores by bio sediments, since the 
water hyacinth was already subjected to relatively higher temperature of $100^{\circ} \mathrm{C}$ making it an ash material the chances of rejuvenation of bio growth within the paver blocks during the rains in also got ruled out.

\section{Strength analysis for conventional Paver Block Vs Biosorption Paver Block}

Being a utility block rather than a building block, the strength analysis for the paver block compared was limited only to the compression test and the flexural strength test. The compressive for the biosorption paver block was reckoned as $22.41 \mathrm{MPa}$ after 3 days curing, $30.87 \mathrm{MPa}$ after 7 days curing and $42.40 \mathrm{MPa}$ after 28 days curing as regards the conventional concrete paver block as the control the same ware observed as $21.52 \mathrm{MPa}, 29.80 \mathrm{MPa}$ and $41.40 \mathrm{MPa}$ respectively. By the same token the flexural strength test was also conducted for ascertaining the resistance against bending.

Table-1: Results of Compressive and Flexural Strength conventional Paver Block Vs Biosorption Paver Block

\begin{tabular}{c|c|c|c|c|c|c|c}
\hline \multirow{2}{*}{ S.No. } & \multirow{2}{*}{ Specimen } & \multicolumn{2}{|c|}{ Compressive Strength in MPa } & \multicolumn{3}{c}{ Flexural strength in MPa } \\
\cline { 3 - 7 } & 3 days & 7 days & 28 days & 3 days & 7 days & 28 days \\
\hline 1. & $\begin{array}{c}\text { Conventional } \\
\text { Paver Block }\end{array}$ & 21.52 & 29.80 & 41.40 & 2.76 & 3.73 & 5.42 \\
\hline 2. & $\begin{array}{c}\text { Bio-sorption } \\
\text { Paver Blocks }\end{array}$ & 22.41 & 30.87 & 42.40 & 2.98 & 4.03 & 5.69 \\
\hline
\end{tabular}

In case of biosorption paver blocks the flexural strength values were registered as $2.98 \mathrm{MPa}$ after3 days, $4.03 \mathrm{MPa}$ after 7 days and $5.69 \mathrm{MPa}$ after 28 days, the same for conventional paver block were noted as 2.76MPa, 3.73MPa and 5.42MPa respectively.

\section{Regression analysis}

In order to corroborate the relative supremacy of biosorpted paver blocks over the conventional industry standard concrete paver block, the test observational were subjected to a regression analysis.

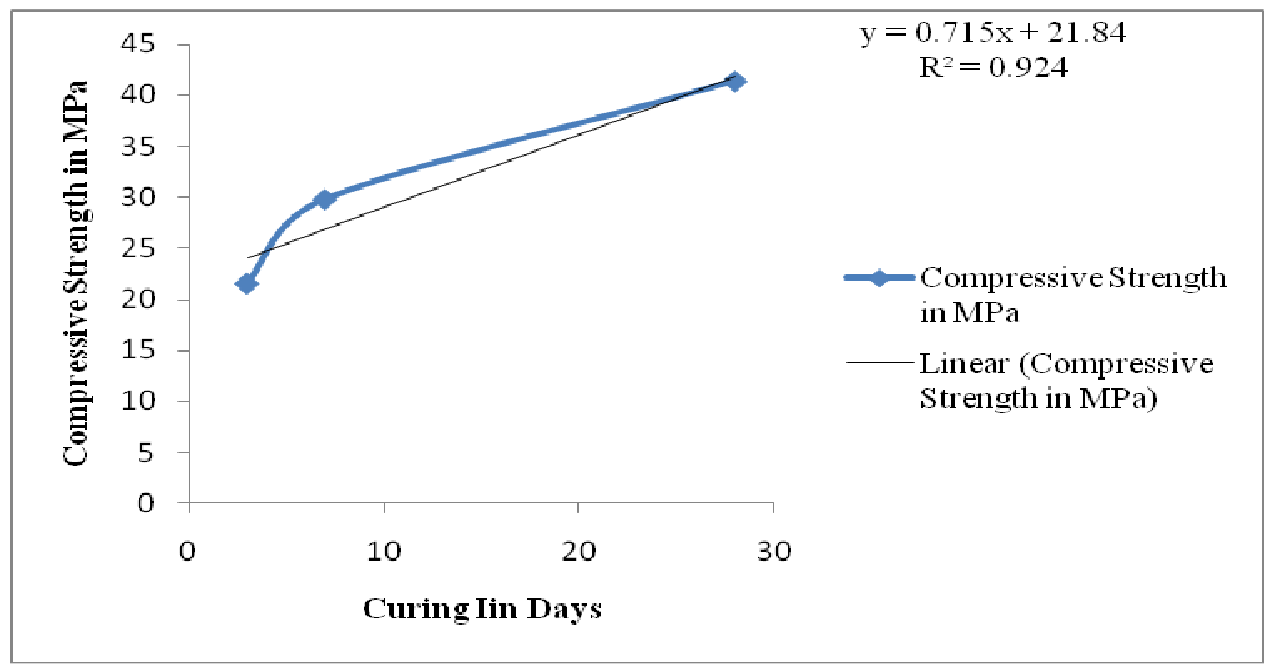

Fig.-1: Compressive Strength Vs. Curing Spells for Concrete Paver Blocks

The compressive and flexural test observation after stipulated intervals of time such as 3 days, 7 days, 28 days of curing can only indicate the relative increase in strength rather than an approximate daily rate of increase in strength the regression analysis balances all these time dependent variations in a linear fashion or non-linear fashion depending upon the synergy between the variables. As far the regression modeling 
is concerned, the present investigation revealed only a satisfactory linear trend of variation at more than 90\% correlation dependability rather than a complicated multiple regression.

The regressions on compressive strength and flexural strength for biosorpted paver block were obtained as an empirical model $y=0.712 x+22.830$ at a dependable correlation coefficient of $R^{2}=91.90 \%$ the implies that the instantaneous starting compressive strength was realized as $22.83 \mathrm{MPa}$ with subsequently daily rates of increase in the strength at $0.712 \mathrm{MPa}$ per day facilitating interpolations within the stipulated curing duration and extrapolations beyond the 28 days curing period.

By the same token, the regression model obtained for the conventional concrete block was $y=0.715 \mathrm{x}+$ 21.084 with a correlation level of $92.40 \%$. This also implies that the initial compressive strength at the start of the curing period stood at $21.84 \mathrm{MPa}$, a bit lower than the biosorption block regression. However the relative daily rate of increase in strength was found to be at a higher value of $0.715 \mathrm{MPa}$ per day suggesting that for the biosorpted blocks the infusion with dry bio materials in between the solid concrete materials may slightly hamper the rate of attaining the strength. Eventually it is understood that replacement of potable water with biosorpted water is making paver block is not going to affect the per day rate of gaining in strength till the end of curing period hence the biosorption concrete paver blocks can be endorsed on par with the conventional concrete paver blocks from the stand point of view with standing normal compressive loads.

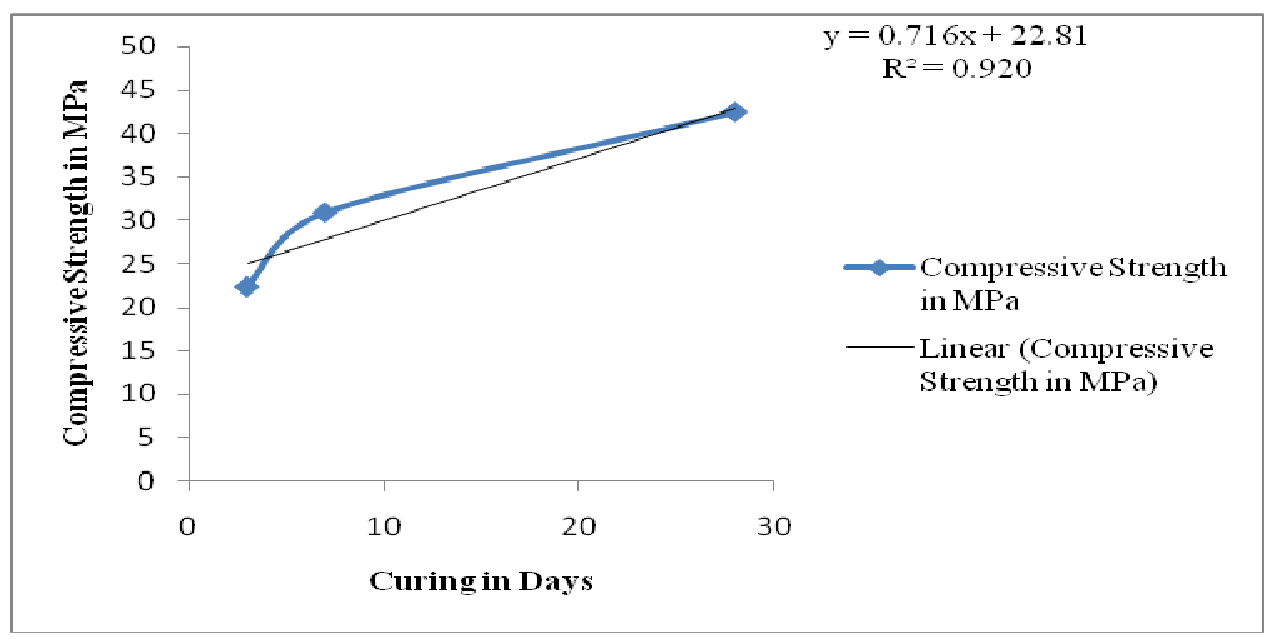

Fig.-2: Compressive Strength Vs. Curing Spells for Biosorpted Paver Blocks

Since the compressive strength performance was on par with or slightly better for biosorption blocks over the conventional blocks, it goes without saying that the flexural strength will also be realized in the same line. The regression equation for flexural strength attained by the biosorpted block suggest a daily rate of increase at $0.097 \mathrm{MPa}$ per day over and above the initial strength of $2.98 \mathrm{MPa}$ a at confidence level of $94.10 \%$. Similar trend was also observed with the conventional block at a daily rate of increase in strength by $0.098 \mathrm{MPa}$ per day over and above an initial curing strength of $2.73 \mathrm{MPa}$ a confidence level of $95 \%$.

\section{CONCLUSION}

By and large, this investigation happens to be a stepping stone trial and error process in ascertaining the relative strength dependency of improvised paver block with the addition of biosorption water in place of the preferable potable water the results are satisfactory by both experimentation as well as regression that the addition of biosorption water as a totally replacement to potable water has not produced any adverse effects, Hence it is concluded that a significant saving on the usage of potable water can be achieved by a simple replacement with biosorption water without detrimental to the structural and functional aspects of paver block compared to the conventional industrial standard paver block. 
RASĀYAN J. Chem.

Vol. 10 | No. 2 |558-563 | April - June | 2017

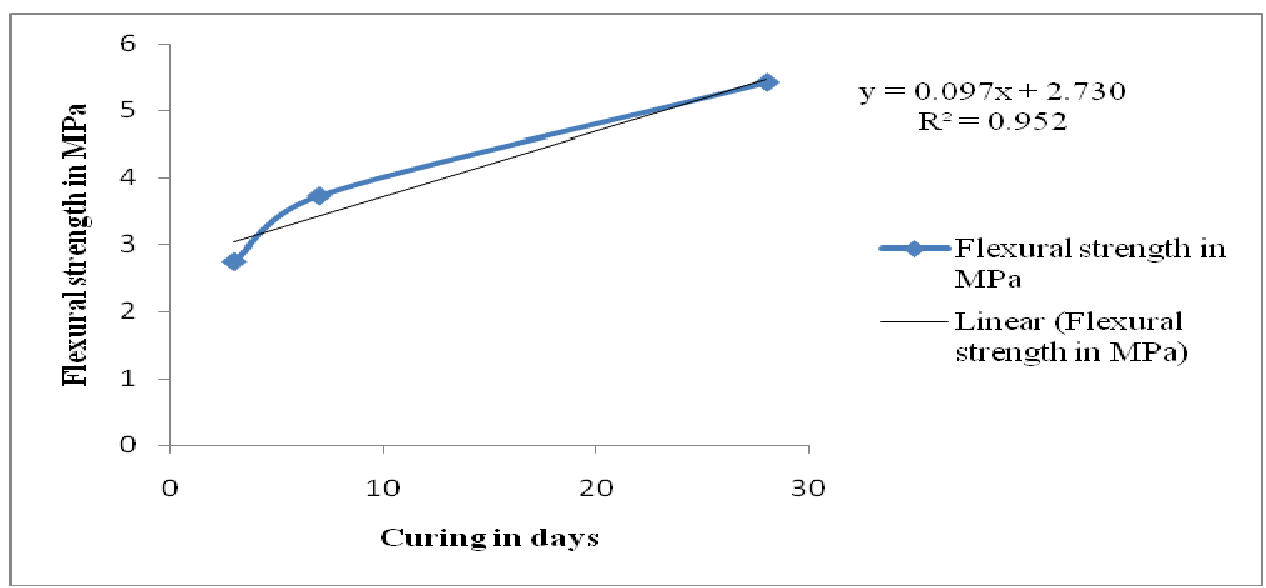

Fig.-3: Flexural Strength Vs. Curing Spells for Conventional Paver Blocks

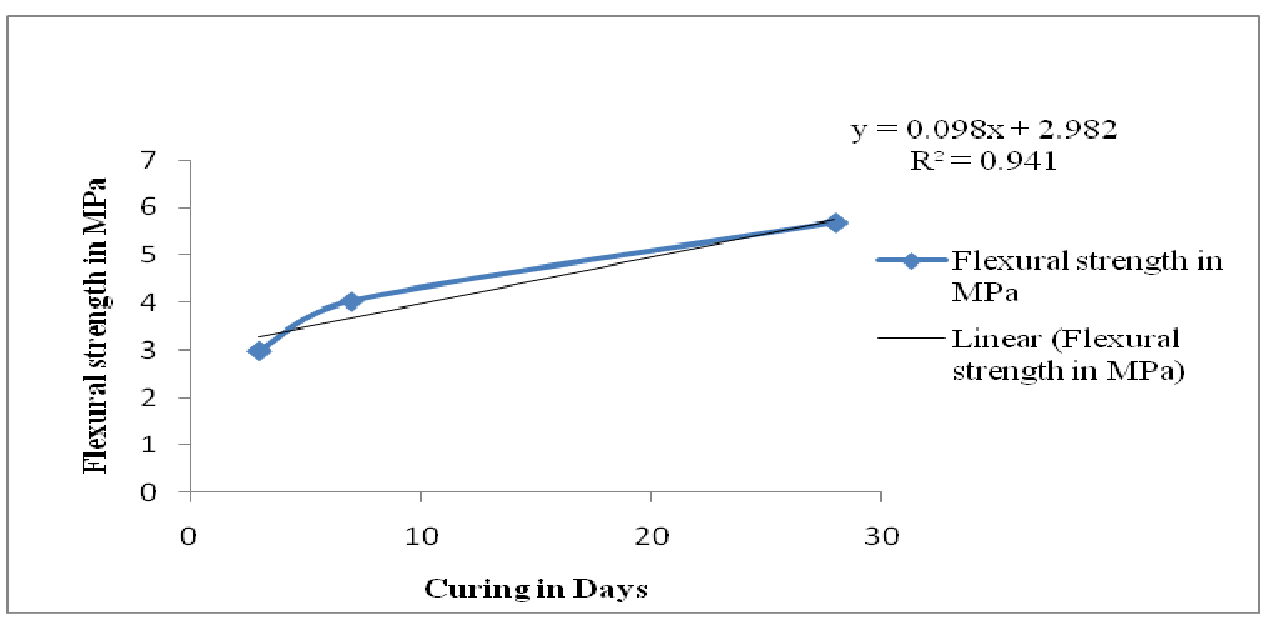

Fig.-4: Flexural Strength Vs. Curing Spells for Biosorpted Paver Blocks

\section{REFERENCES}

1. Chi-Sun Poon and Dixon Chan, Construction and Building Materials, 20(8), 569(2006).

2. Ksenija Jankovic, Dragan Nikolic and Dragan Bojovic, Construction and Building Materials, 28(1), 659 (2012).

3. Savaş Erdem, Marva Angela Blankson, Journal of Hazardous Materials, 264, 403(2014).

4. BIS: 15658, Precast concrete blocks for paving- Specification, 1, 1(2006).

5. BIS: 456, Plain and Reinforced concrete-code of practice, 4, 1(2000).

6. BIS: 383, Specification for coarse and fine aggregate from natural sources for concrete, 2, 1(1970).

7. BIS: 8112, Specification for 43 grade Ordinary Portland Cement, India, pp.1-10 (1989).

[RJC-1733/2017] 